\title{
Maternal PAPP-A Levels at 11 - 13 Weeks of Gestation Predict Foetal and Neonatal Growth
}

\section{-PAPP-A Growth Predictor}

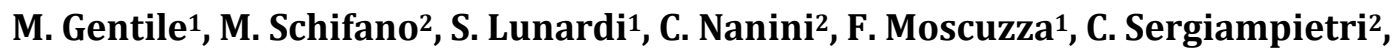 \\ M. Ciantelli' ${ }^{1}$, F. Monacci², A. Boldrini' ${ }^{1}$, C. Luchi' ${ }^{2}$, P. Ghirri ${ }^{*}{ }^{*}$ \\ ${ }^{1}$ Department of Clinical and Experimental Medicine, Neonatal Intensive Care and Neonatology Unit, University \\ Hospital of Pisa, Pisa, Italy \\ ${ }^{2}$ Department of Clinical and Experimental Medicine, Division of Obstetrics and Gynaecology, University \\ Hospital of Pisa, Pisa, Italy \\ Email: *pghirri@med.unipi.it
}

Received 1 May 2015; accepted 21 June 2015; published 24 June 2015

Copyright (C) 2015 by authors and Scientific Research Publishing Inc.

This work is licensed under the Creative Commons Attribution International License (CC BY).

http://creativecommons.org/licenses/by/4.0/

(c) (i) Open Access

\section{Abstract}

Recent reports suggest that maternal serum levels of pregnancy-associated plasma protein $A$ (PAPP-A) may predict perinatal outcome. PAPP-A is a syncytiotrophoblast derived protease for insulin-like growth factor binding protein (IGFBP4); its protease activity cleaves complexed growth factor binding protein increasing insulin-like growth factor I (IGF-I) bioavailability. The aim of our study was to evaluate the correlation between maternal PAPP-A serum levels and neonatal growth. We analysed 100 full term and preterm (30 - 36 weeks) small for gestational age (SGA) and adequate for gestational age (AGA) babies whose mothers had been tested for serum PAPP-A at 11 13 weeks of gestation. We found a significant positive correlation between maternal PAPP-A and neonatal weight, length, and head circumference at birth in both term and preterm infants. Low maternal PAPP-A serum levels (maternal PAPP-A $<0.5$ ) were associated with small for gestational age neonates. A significant positive correlation was also evident between maternal PAPP-A and babies' growth parameters at 6 months of age. Our results suggest that maternal levels of PAPP-A in early pregnancy affect growth during both foetal and early postnatal life.

\section{Keywords}

Maternal Predictors, Foetal Growth, Neonatal Outcome

\footnotetext{
${ }^{*}$ Corresponding author.
}

How to cite this paper: Gentile, M., Schifano, M., Lunardi, S., Nanini, C., Moscuzza, F., Sergiampietri, C., Ciantelli, M., Monacci, F., Boldrini, A., Luchi, C. and Ghirri, P. (2015) Maternal PAPP-A Levels at 11 - 13 Weeks of Gestation Predict Foetal and Neonatal Growth. Open Journal of Obstetrics and Gynecology, 5, 365-372. http://dx.doi.org/10.4236/ojog.2015.56053 


\section{Introduction}

Recent reports suggest that maternal serum levels of pregnancy-associated plasma protein A (PAPP-A) at 9 - 14 weeks of gestation may predict foetal and neonatal outcome. Several studies reported a correlation between maternal PAPP-A levels during pregnancy and baby's birth weight [1]-[3]. Lower maternal serum PAPP-A levels were, according to a few studies, associated with maternal hypertension during pregnancy [1] [4]-[13]. Large population-based screening studies demonstrated that low levels of PAPP-A were associated with reduced foetal growth [4]-[6] [8]-[10] [12] [14]-[22].

PAPP-A's role in foetal growth is due to its interaction with the insulin-like growth factor (IGF-1) system. Insulin like growth factor seems to play a significant role in trophoblastic invasion [23]-[26], affecting early development and vascularisation of the placenta and the placental bed and activating downstream signaling pathways. IGF-1 is usually bound to circulating proteins that make it more stable. PAPP-A is a syncytiotrophoblastderived protease for insulin-like growth factor binding protein [27]; its protease activity cleaves complexed growth factor enhancing its bioavailability [28] [29]. Thus high PAPP-A concentrations lead to enhanced growth factor bioactivity which leads to enhanced growth [27] [30].

Our objective was to confirm the relationship between first-trimester PAPP-A levels and birth weight hypothesizing that, at a certain point in the first trimester, PAPP-A predicted subsequent placental function and neonatal growth outcome.

\section{Materials and Methods}

We analysed 100 babies born in our Neonatology Unit whose mothers had been tested for serum PAPP-A at 11 13 weeks of gestation. Our sample collected babies from 30 weeks of gestational age both Small for Gestational Age (SGA) and Adequate for Gestational Age (AGA). Neonates with congenital malformations were excluded from our study.

Neonates were divided in 4 groups of 25 babies each according to their gestational age and weight at birth: term SGA babies, term AGA babies, preterm SGA babies, preterm AGA babies. AGA and SGA definition was based on the Bertino's Italian population based growth charts [31]. SGA infants were defined by a birth weight below the 10th percentile for their gestational age (GA), whereas AGA infants were those with a birth weight between the 25th and the 75th percentile.

The following variables were studied: neonatal weight, length and head circumference, placenta's weight, maternal age, neonatal Red Blood Cells (RCB) count and haemoglobin levels at birth. Other neonatal outcomes such as presence of respiratory distress and length of hospitalization were considered as well.

These variables were compared to maternal PAPP-A serum levels at 11 - 13 weeks of gestation by means of a statistical study of linear regression and correlation.

PAPP-A levels were adjusted for other parameters while calculating (first trimester screening program) the risk in each pregnancy: each measured value was converted to a multiple of the median (MoM) specific parameter for GA, maternal weight, ethnic origin, smoking status and method of conception. The biochemical calculation considers various parameters which are, in addition to gestational age derived from the measurement of CRL, mother's weight, ethnic group, smoke of cigarettes, IVF, parity, numbers of foetuses and chorionicity in case of twin pregnancy.

We also studied in preterm infants (both SGA and AGA at birth) auxological outcome at 6 months of corrected age. Weight, length and head circumference at 6 months were defined according to the World Health Organization Child Growth Charts and then compared to maternal PAPP-A levels.

Statistical study was performed by SPSS 16.0.

\section{Results}

The 100 babies we analysed in our study were divided in 4 groups of 25 babies each according to their gestational age and weight at birth: term SGA babies, term AGA babies, preterm SGA babies, preterm AGA babies. Comparing the studied neonatal variables to maternal PAPP-A serum levels at 11 - 13 weeks of gestation we observed a statistically significant positive correlation between maternal PAPP-A MoM levels and neonatal weight (W), length (L) and head circumference (HC) at birth both in term and preterm newborns (Figure 1 and Figure 2). 
We were able to highlight as well a significant positive correlation between PAPP-A MoM levels and placental weight both in term and preterm babies (Figure 1 and Figure 2).
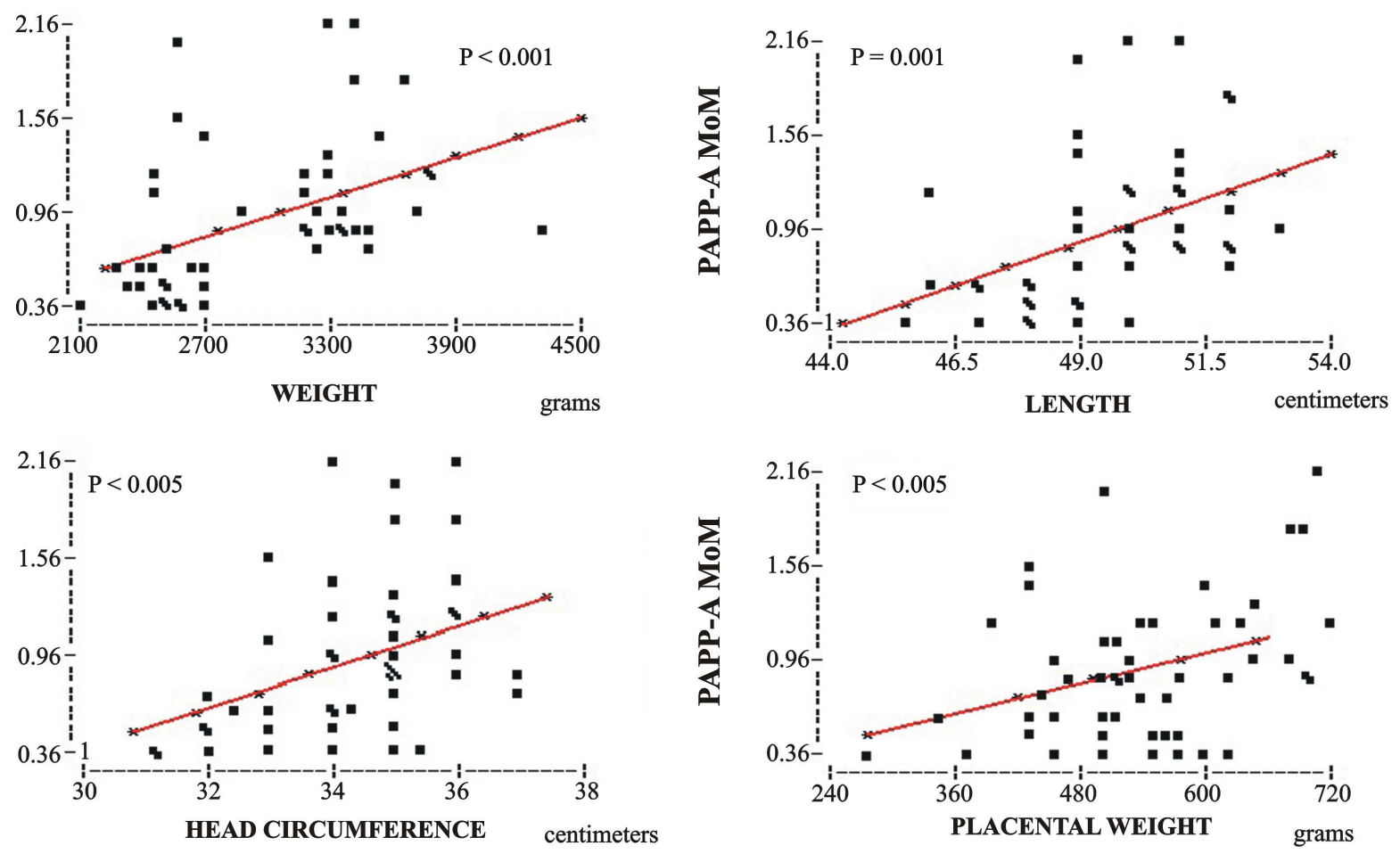

Figure 1. Maternal PAPP-A MoM levels at 11 - 13 weeks of gestation compared to neonatal weight (grams), length (centimeters) and head circumference (centimeters) at birth and placental weight (grams), in term pregnancies.
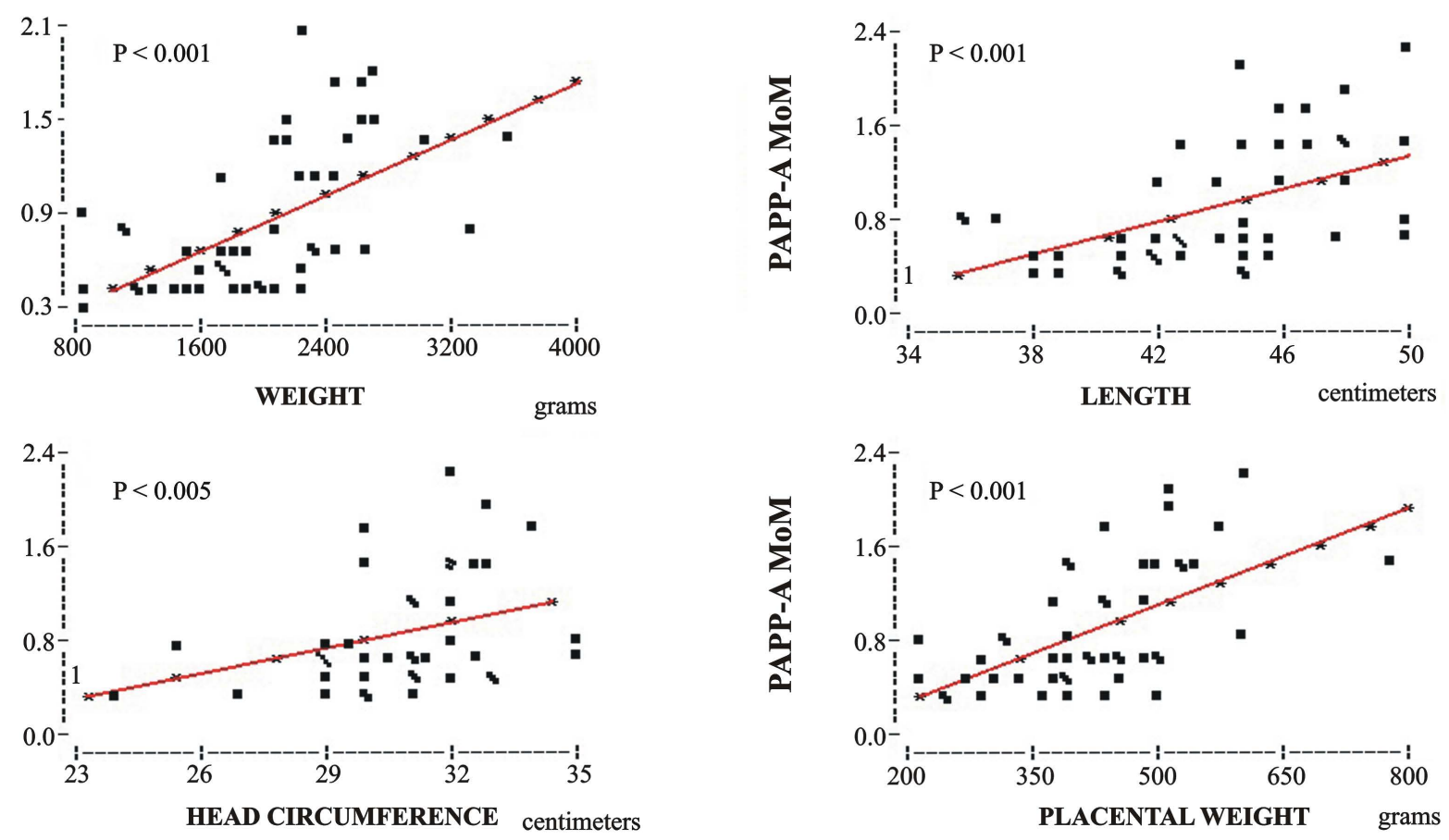

Figure 2. Maternal PAPP-A MoM levels at 11 - 13 weeks of gestation compared to neonatal weight (grams), length (centimeters) and head circumference (centimeters) at birth and placental weight (grams) in preterm pregnancies. 
Table 1. Distribution of SGA babies after grouping them according to MoM values.

\begin{tabular}{|c|c|c|c|}
\hline & \multicolumn{3}{|c|}{ Distribution of SGA ${ }^{a}$ babies after grouping them according to MoM values } \\
\hline & MoM $<0.5$ & MoM 0.5 - 1 & MoM 1 - 1.5 \\
\hline SGA preterm babies ( 25 cases) & $\begin{array}{c}11 \text { SGA for } W^{\mathbf{b}}, \mathrm{L}^{\mathbf{c}}, \mathrm{HC}^{\mathbf{d}} \\
\text { 2 SGA for W, L } \\
\text { 3 SGA for } \mathrm{W}, \mathrm{HC}\end{array}$ & $\begin{array}{l}4 \text { SGA for W, L } \\
4 \text { SGA for W, HC }\end{array}$ & 1 SGA for $\mathrm{W}$ \\
\hline SGA full term babies ( 25 cases) & $\begin{array}{l}10 \text { SGA for W, L, HC } \\
4 \text { SGA for W, L }\end{array}$ & $\begin{array}{l}\text { 2 SGA for } \mathrm{W}, \mathrm{L} \\
3 \mathrm{SGA} \text { for } \mathrm{W}, \mathrm{HC}\end{array}$ & 6 SGA for $\mathrm{W}$ \\
\hline
\end{tabular}

${ }^{\mathrm{a}}$ Small for gestational age babies; ${ }^{\mathrm{b}}$ Weight; ${ }^{\mathrm{c}}$ Length; ${ }^{\mathrm{d}} \mathrm{Head}$ circumference.

No statistically significant correlation was found instead between PAPP-A MoM levels and maternal age, neonatal red blood cells count and haemoglobin levels at birth, incidence of persistent periventricular hyperechogenicity (lasting more than 14 days) and length of stay in hospital in preterm AGA and SGA babies.

Moreover, analysing all babies whose mother had a PAPP-A MoM $<0.5$, it was shown that both full term and preterm neonates were SGA for weight and at least another anthropometric parameter (2/3 of neonates were SGA for weight, height and head circumference) (Table 1) [32].

Levels of PAPP-A MoM between 0.5 and 1 were associated with infants SGA for two anthropometric parameters (weight and height/or weight and head circumference). PAPP-A > 1.5 was associated instead in all cases to the birth of an AGA newborn (no matter what the gestational age was).

We also examined whether in case of SGA infant with PAPP-A MoM $<0.5$ the mother had suffered from any kind of disease during pregnancy. Maternal gestosis or diabetes had occured in 15 preterm SGA babies and in 8 term SGA newborns.

The evaluation of correlation between the placental weight and the neonatal parameters showed that in both AGA and SGA preterm babies there was a significant positive correlation between birth weight, length, head circumference and placental weight.

\section{Follow-Up}

We evaluated the growth of our SGA and AGA premature babies at 6 months of corrected age. A linear, positive and significant correlation between weight ( $p$ 0.029), length ( $p$ 0.036), cranial circumference ( $p$ 0.016) and PAPP-A maternal levels was still detectable at 6 months of age (Figure 3).

At 6 months of corrected age weight, length and head circumference of SGA preterm babies were still below the 10 th centile respectively in $80 \%, 76 \%$ and $60 \%$ of them.

\section{Discussion}

Our study supports the idea that the majority of pregnancies leading to SGA infants are complicated by gestosis or diabetes (in our study 15 out of 25 premature SGA babies and 8 out of 25 full term SGA babies were born to mothers with gestosis or diabetes). The levels of PAPP-A MoM were $\leq 0.5$ in these pregnancies. This confirms that low levels of PAPP-A are not associated with a positive outcome of pregnancy.

Recent multicenter studies showed that levels of PAPP-A below the 5th centile in the first trimester of pregnancy are more frequently associated with intrauterine death, premature birth, preeclampsia and low birth weight [4]-[6] [8] [9] [12] [14]-[16] [33] [34].

In our study we demonstrated that there is a significant, positive correlation between PAPP-A plasma levels and birth weight, length, head circumference and placenta's weight.

PAPP-A is a protease of IGFBP4 which acts as a binding protein for IGF-1 and a powerful inhibitor for IGF-1. Therefore, low levels of PAPP-A are associated with high levels of IGFPB4 and consequently with reduced levels of free circulating IGF-1. IGF-1 plays an important role in regulating foetal growth by controlling glucose and amino acids absorption in trophoblastic cells.

We think that PAPP-A plays as well a significant role in controlling autocrine and paracrine trophoblastic invasion. Thus low levels of PAPP-A could cause an inadequate trophoblastic invasion and consequently an higher incidences of abortions, premature labours, low birth weight and preeclampsia [27] [28].

Instead, high PAPP-A levels cause more IGFBP4 proteolysis increasing free IGF-1 circulating levels. Thus, 


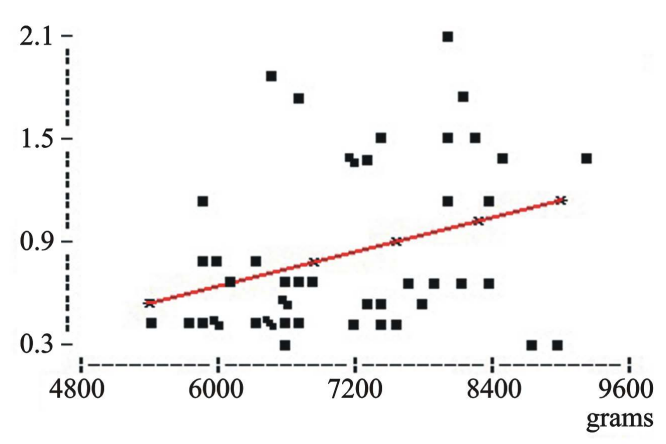

(a)

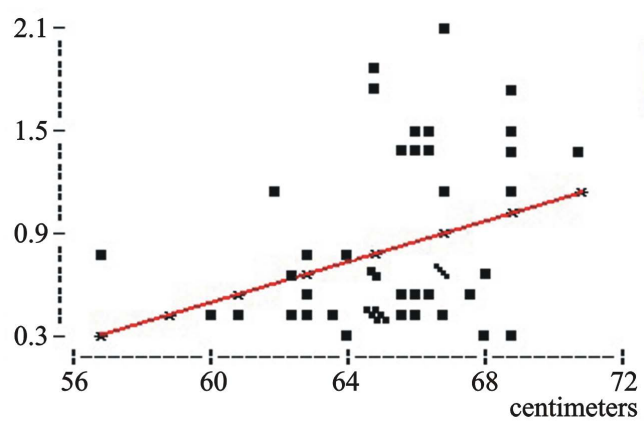

(b)

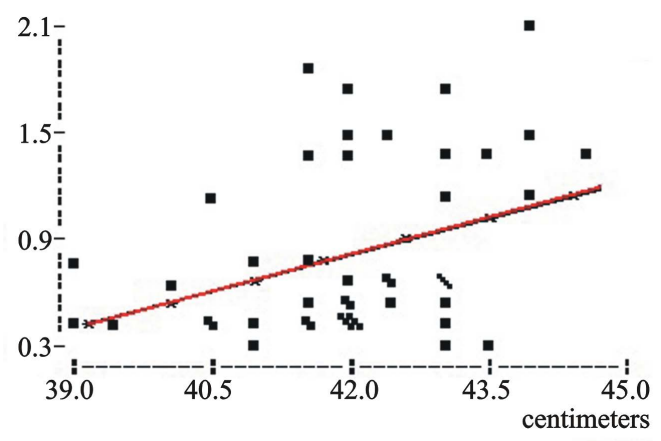

(c)

Figure 3. 6 months follow-up: correlation between (a) weight (grams); (b) length (centimeters); (c) head circumference (centimeters) and maternal PAPP-A MoM.

we could expect a positive correlation between high levels of PAPP-A ( $>90$ th percentile) and foetal macrosomia. In our study we analysed only 3 infants with high levels of PAPP-A (PAPP-A MoM > 2) and only one of them had a birth weight $>97$ th percentile (the other two cases weighed between the 75th and the 90th percentile). More studies will be necessary to verify the correlation between high levels of PAPP-A and macrosomia.

As far as preterm and term SGA infants are concerned, PAPP-A MoM levels $<0.5$ are associated with $70 \%$ of babies SGA for three anthropometric parameters (W, L and HC). Levels of PAPP-A MoM between 0.5 and 1 were associated with infants SGA for two anthropometric parameters (weight and height/or weight and head circumference). Levels of PAPP-A MoM > 1.5 were all associated with the birth of AGA infants.

Furthermore in our study PAPP-A levels correlate with weight, height and head circumference at 6 months suggesting that higher levels of free IGF1 during foetal life due to higher levels of maternal PAPP-A may affect foetal and early postnatal growth.

Moreover the correlation between PAPP-A levels and head circumference at 6 months suggests that probably low levels of circulating IGF1 are associated to smaller head circumferences.

IGF1 is important for foetal and early infantile neurological development. In particular, it plays an important role in neuroprotection by reducing neuronal death caused by different types of injuries [35]. 
Further studies should be carried out in order to evaluate the relationship between PAPP-A levels, IGF1 and neurological development in the first years of life.

\section{Conclusions}

In conclusion, values of PAPP-A MoM $<0.5$ at 11 - 13 weeks of gestational age are predictive for unfavourable outcome of pregnancy and birth of infants SGA for weight, length and/or cranial circumference.

Even if further and wider studies on the topic would be useful to confirm our hypothesis, we can conclude that in case of MoM $<0.5-1$ a closer monitoring of pregnancy, a labour planning in a II-III level centre and a careful auxological follow-up in the first years of life are recommended.

\section{References}

[1] Tul, N., Pusenjak, S., Osredkar, J., Spencer, K. and Novak-Antolic, Z. (2003) Predicting Complications of Pregnancy with First-Trimester Maternal Serum Free-betahCG, PAPP-A and Inhibin-A. Prenatal Diagnosis, 23, 990-996. http://dx.doi.org/10.1002/pd.735

[2] Canini, S., Prefumo, F., et al. (2008) Association between Birthweight and First-Trimester Free b-Human Chorionic Gonadotropin and Pregnancy-Associated Plasma Protein A. Fertility and Sterility, 89, 174-178. http://dx.doi.org/10.1016/j.fertnstert.2007.02.024

[3] Boucoiran, I., Djemli, A., Taillefer, C., Rypens, F., Delvin, E. and Audibert, F. (2013) First-Trimester Prediction of Birth Weight. American Journal of Perinatology, 30, 665-672. http://dx.doi.org/10.1055/s-0032-1331023

[4] Morssink, L.P., Kornman, L.H., Hallahan, T.W., Kloosterman, M.D., Beekhuis, J.R., de Wolf, B.T., et al. (1998) Maternal Serum Levels of Free Beta-hCG and PAPP-A in the First Trimester of Pregnancy Are Not Associated with Subsequent Fetal Growth Retardation or Preterm Delivery. Prenatal Diagnosis, 18, 147-152. http://dx.doi.org/10.1002/(SICI)1097-0223(199802)18:2<147::AID-PD231>3.0.CO;2-W

[5] Ong, C.Y., Liao, A.W., Spencer, K., Munim, S. and Nicolaides, K.H. (2000) First Trimester Maternal Serum Free Beta Human Chorionic Gonadotrophin and Pregnancy Associated Plasma Protein A as Predictors of Pregnancy Complications. BJOG, 107, 1265-1270. http://dx.doi.org/10.1111/j.1471-0528.2000.tb11618.x

[6] Smith, G.C., Stenhouse, E.J., Crossley, J.A., Aitken, D.A., Cameron, A.D. and Connor, J.M. (2002) Early Pregnancy Levels of Pregnancy-Associated Plasma Protein A and the Risk of Intrauterine Growth Restriction, Premature Birth, Pre-Eclampsia, and Stillbirth. Journal of Clinical Endocrinology Metabolism, 87, 1762-1767. http://dx.doi.org/10.1210/jcem.87.4.8430

[7] Tsai, M.S., Lee, F.K., Cheng, C.C., Hwa, K.Y., Cheong, M.L. and She, B.Q. (2002) Association between Fetal Nuchal Translucency Thickness in First Trimester and Subsequent Gestational Hypertension and Preeclampsia. Prenatal Diagnosis, 22, 747-751. http://dx.doi.org/10.1002/pd.396

[8] Yaron, Y., Heifetz, S., Ochshorn, Y., Lehavi, O. and Orr-Urtreger, A. (2002) Decreased First Trimester PAPP-A Is a Predictor of Adverse Pregnancy Outcome. Prenatal Diagnosis, 22, 778-782. http://dx.doi.org/10.1002/pd.407

[9] Kwik, M. and Morris, J. (2003) Association between First Trimester Maternal Serum Pregnancy Associated Plasma Protein-A and Adverse Pregnancy Outcome. Australian and New Zealand Journal of Obstetrics and Gynaecology, 43, 438-442. http://dx.doi.org/10.1046/j.0004-8666.2003.00126.x

[10] Dugoff, L., Hobbins, J.C., Malone, F.D., Porter, T.F., Luthy, D., Comstock, C.H., et al. (2004) First-Trimester Maternal Serum PAPP-A and Free-Beta Subunit Human Chorionic Gonadotropin Concentrations and Nuchal Translucency Are Associated with Obstetric Complications: A Population-Based Screening Study (the FASTER Trial). American Journal of Obstetrics Gynecology, 191, 1446-1451. http://dx.doi.org/10.1016/j.ajog.2004.06.052

[11] Krantz, D., Goetzl, L., Simpson, J.L., Thom, E., Zachary, J., Hallahan, T.W., et al. (2004) Association of Extreme First-Trimester Free Human Chorionic Gonadotropin- $\beta$, Pregnancy-Associated Plasma Protein A, and Nuchal Translucency with Intrauterine Growth Restriction and Other Adverse Pregnancy Outcomes. American Journal of Obstetrics and Gynecology, 191, 1452-1458. http://dx.doi.org/10.1016/j.ajog.2004.05.068

[12] Smith, G.C., Stenhouse, E.J., Crossley, J.A., Aitken, D.A., Cameron, A.D. and Connor, J.M. (2002) Early Pregnancy Levels of Pregnancy-Associated Plasma Protein A and the Risk of Intrauterine Growth Restriction, Premature Birth, Preeclampsia, and Stillbirth. The Journal of Clinical Endocrinology \& Metabolism, 87, 1762-1767.

[13] Krantz, D., Goetzl, L., Simpson, J.L., Thom, E., Zachary, J., Hallahan, T.W., et al. (2004) Association of Extreme First-Trimester Free Human Chorionic Gonadotropin-Beta, Pregnancy-Associated Plasma Protein A, and Nuchal Translucency with Intrauterine Growth Restriction and Other Adverse Pregnancy Outcomes. American Journal of Obstetrics Gynecology, 191, 1452-1458. http://dx.doi.org/10.1016/j.ajog.2004.05.068

[14] Law, L.W., Leung, T.Y., Sahota, D.S., Chan, L.W., Fung, T.Y. and Lau, T.K. (2009) Which Ultrasound or Biochemi- 
cal Markers Are Independent Predictors of Small-for-Gestational Age. Ultrasound in Obstetrics and Gynecology, 34, 247-248. http://dx.doi.org/10.1002/uog.6455

[15] Smith, G.C., Shah, I., Crossley, J.A., Aitken, D.A., Pell, J.P., Nelson, S.M., et al. (2006) Pregnancy-Associated Plasma Protein A and Alpha-Fetoprotein and Prediction of Adverse Perinatal Outcome. Obstetrics Gynecology, 107, 161-166. http://dx.doi.org/10.1097/01.AOG.0000191302.79560.d8

[16] Peterson, S.E. and Simhan, H.N. (2008) First-Trimester Pregnancy-Associated Plasma Protein A and Subsequent Abnormalities of Fetal Growth. American Journal of Obstetrics \& Gynecology, 198, e43-e45. http://dx.doi.org/10.1016/j.ajog.2007.12.026

[17] Smith, G.C., Stenhouse, E.J., Crossley, J.A., Aitken, D.A., Cameron, A.D. and Connor, J.M. (2002) Early-Pregnancy Origins of Low Birth Weight. Nature, 417, 916. http://dx.doi.org/10.1038/417916a

[18] Pedersen, J.F., Sorensen, S. and Ruge, S. (1995) Human Placental Lactogen and Pregnancy-Associated Plasma Protein A in First Trimester and Subsequent Fetal Growth. Acta Obstetricia et Gynecologica Scandinavica, 74, 505-508. http://dx.doi.org/10.3109/00016349509024379

[19] Smith, G.C., Crossley, J.A., Aitken, D.A., Pell, J.P., Cameron, A.D., Connor, J.M., et al. (2004) First-Trimester Placentation and the Risk of Antepartum Stillbirth. Journal of the American Medical Association, 292, 2249-2254. http://dx.doi.org/10.1001/jama.292.18.2249

[20] Conover, C.A., Bale, L.K., Overgaard, M.T., Johnstone, E.W., Laursen, U.H., Füchtbauer, E.M., et al. (2004) Metalloproteinase Pregnancy-Associated Plasma Protein A Is a Critical Growth Regulatory Factor during Fetal Development. Development, 131, 1187-1194. http://dx.doi.org/10.1242/dev.00997

[21] Cowans, N.J. and Spencer, K. (2007) First-Trimester ADAM12 and PAPP-A as Markers for Intrauterine Fetal Growth Restriction through Their Roles in the Insulin-Like Growth Factor System. Prenatal Diagnosis, 27, 264-271. http://dx.doi.org/10.1002/pd.1665

[22] Poon, L.C., Karagiannis, G., Staboulidou, I., Shafiei, A. and Nicolaides, K.H. (2011) Reference Range of Birth Weight with Gestation and First-Trimester Prediction of Small-for-Gestation Neonates. Prenatal Diagnosis, 31, 58-65. http://dx.doi.org/10.1002/pd.2520

[23] Irwin, J.C., Suen, L.F., Martina, N.A., Mark, S.P. and Giudice, L.C. (1999) Role of the IGF System in Trophoblast Invasion and Preeclampsia. Human Reproduction, 14, S90-S96. http://dx.doi.org/10.1093/humrep/14.suppl_2.90

[24] Dugoff, L., Hobbins, J.C., Malone, F.D., Porter, T.F., Luthy, D., Comstock, C.H., et al. (2004) First-Trimester Maternal Serum PAPP-A and Free-Beta Subunit Human Chorionic Gonadotropin Concentrations and Nuchal Translucency Are Associated with Obstetric Complications: A Population-Based Screening Study (The FASTER Trial). American Journal of Obstetrics Gynecology, 191, 1446-1451. http://dx.doi.org/10.1016/j.ajog.2004.06.052

[25] Lau, H., Amarasekara, C. and Uppal, T. (2012) Low PAPP-A: What Are the Clinical Implications? AJUM, 15, $26-28$.

[26] Loncar, D., Varjacić, M. and Arsenijević, S. (2013) Significance of Pregnancy-Associated Plasma Protein A (PAPP-A) Concentration Determination in the Assessment of Final Outcome of Pregnancy. Vojnosanitetski Pregled, 70, 46-50. Malik, A.S., Boyko, O., Atkar, N. and Young, W.F. (2001) A Comparative Study of MR Imaging Profile of Titanium Pedicle Screws. Acta Radiologica, 42, 291-293. http://dx.doi.org/10.1080/028418501127346846

[27] Laurence, J.B., Oxvig, C., Overgaard, M.T., Sottrup-Jensen, L., Gleich, G.J., Hays, L.G., et al. (1999) The Insulin-Like Growth Factor (IGF)-Dependent IGF Binding Protein-4 Protease Secreted by Human Fibroblasts Is Pregnancy-Associated Plasma Protein-A. Proceedings of the National Academy of Sciences, 96, 3149-3153. http://dx.doi.org/10.1073/pnas.96.6.3149

[28] Bonno, M., Oxvig, C., Kephart, G.M., Wagner, J.M., Kristensen, T., Sottrup-Jensen, L. and Gleich, G.J. (1994) Localization of Pregnancy-Associated Plasma Protein-A and Colocalization of Pregnancy-Associated Plasma Protein-A Messenger Ribonucleic Acid and Eosinophil Granule Major Basic Protein Messenger Ribonucleic Acid in Placenta. Laboratory Investigation, 71, 560-566.

[29] Lawrence, J.B., Oxvig, C., Overgaard, M.T., Sottrup-Jensen, L., Gleich, G.J., Hays, L.G., et al. (1999) The Insulin-Like Growth Factor (IGF)-Dependent IGF Binding Protein-4 Protease Secreted by Human Fibroblasts Is Pregnancy-Associated Plasma Protein-A. Proceedings of the National Academy of Sciences, 96, 3149-3153. http://dx.doi.org/10.1073/pnas.96.6.3149

[30] Spencer, K., Cowans, N.J., Avgidou, K., Molina, F. and Nicolaides, K.H. (2008) First-Trimester Biochemical Markers of Aneuploidy and the Prediction of Small-for-Gestational Age Fetuses. Ultrasound in Obstetrics and Gynecology, 31, 15-19. http://dx.doi.org/10.1002/uog.5165

[31] Bertino, E., Spada, E., Occhi, L., Coscia, A., Giuliani, F., Gagliardi, L., et al. (2010) Neonatal Anthropometric Charts: The Italian Neonatal Study Compared with Other European Studies. Journal of Pediatric Gastroenterology and Nutrition, 51, 353-361. http://dx.doi.org/10.1097/mpg.0b013e3181da213e

[32] Gigante, D.P, Horta, B.L., Lima, R.C., Barros, F.C. and Victora, C.G. (2006) Early Life Factors Are Determinants of 
Female Height at Age 19 Years in a Population-Based Birth Cohort (Pelotas, Brazil). Journal of Nutrition, 136, 473478.

[33] Goetzinger, K.R., Singla, A., Gerkowicz, S., Dicke, J.M., Gray, D.L. and Odibo, A.O. (2009) The Efficiency of First-Trimester Serum Analytes and Maternal Characteristics in Predicting Fetal Growth Disorders. American Journal of Obstetrics and Gynecology, 201, 412.e1-412.e6.

[34] Montanari, L., Alfei, A., Albonico, G., Moratti, R., Arossa, A., Beneventi, F. and Spinillo, A. (2009) The Impact of First-Trimester Serum Free Beta-Human Chorionic Gonadotropin and Pregnancy-Associated Plasma Protein A on the Diagnosis of Fetal Growth Restriction and Small for Gestational Age Infant. Fetal Diagnosis and Therapy, 25, 130135.

[35] Górecki, D.C., Beresewicz, M. and Zabłocka, B. (2007) Neuroprotective Effects of Short Peptides Derived from the Insulin-Like Growth Factor 1. Neurochemistry International, 51, 451-458. http://dx.doi.org/10.1016/j.neuint.2007.04.030 